\title{
EFeitos da AdubaçÃo Fosfatada nas Relações de INTERFERÊnCia Inicial entre Plantas de Milho (Zea mays) E DE TIRIRICA (Cyperus rotundus) ${ }^{1}$
}

\author{
Effects of Phosphorus Fertilization on the Initial Interference Relationship Involving Maize and \\ Purple Nutsedge
}

\begin{abstract}
SALGADO, T.P. ${ }^{2}$, PITELLI, R.A. ${ }^{3}$, ALVES, P.L.C.A. ${ }^{3}$, SALVADOR, F.L. ${ }^{4}$ e NUNES, A.S. ${ }^{4}$
RESUMO - O objetivo deste trabalho foi avaliar os efeitos da adubação fosfatada nas relações de interferência inicial entre plantas de milho e de tiririca. Para isso, foi montado um experimento em vasos de $90 \mathrm{~L}$, preenchidos com substrato constituído por areia, terra e substrato Plantmax®. Os tratamentos constaram de combinações de colonização dos vasos por milho e/ou por tiririca nas densidades iniciais de 25 e 50 tubérculos por vaso; essas situações de colonização foram estabelecidas em três condições de adubação fosfatada adicional: 0,100 e 300 ppm de fósforo. No campo, os vasos foram dispostos no delineamento inteiramente casualizado, com quatro repetições. As relações de interferência entre plantas de milho e de tiririca foram alteradas pela fertilização fosfatada do solo. O milho teve excelente aproveitamento do enriquecimento do solo pelo fósforo e interferiu mais decisivamente sobre a tiririca nos vasos bem fertilizados com esse elemento. Nessas condições, o milho reduziu drasticamente a resposta da tiririca à fertilização fosfatada, em termos de crescimento da parte aérea. A interferência da tiririca reduziu a altura das plantas de milho, a expansão da área foliar e o acúmulo de matéria seca na parte aérea.
\end{abstract}

Palavras-chave: competição, fósforo, planta daninha, densidade.

\begin{abstract}
The objective of this paper was to evaluate the influence of phosphorus fertilization on the interference relationship between maize and purple nutsedge plants. An experiment was set up in 90L pots filled up with a mix of sand, soil and commercial substrate PlantMax®. The experimental treatments were combinations of pot colonization by maize and/or purple nutsedge; initial density of purple nutsedge tubers (25 or 50 tubers/pot) and three doses of phosphorus fertilization (increase of soil phosphorus level in 0,100 and $300 \mathrm{ppm}$ ). The interference relationships between the two species were affected by phosphorus fertilization. The maize plants showed excellent response to phosphorus fertilization and improved its interference in purple nutsedge plants and drastically reduced the weed response to phosphorus soil amendment. Maize interference reduced the number and dry matter accumulation of purple nutsedge shoots and tubers. Under the maize interference, purple nutsedge showed higher resources partitioning to tubers than to shoots. Purple nutsedge interference reduced maize plant height, dry matter accumulation in leaves and stems and leaf area expansion.
\end{abstract}

Keywords: competition, Zea mays, Cyperus rotundus, weed density.

Recebido para publicação em 26.1.2005 e na forma revisada em 24.2.2006.

2 Pós-graduando em Produção Vegetal da FCAV-UNESP, Jaboticabal-SP, <tpsalgado@ herbae.com.br>; ${ }^{3}$ Eng.-Agr., Dr., Professor da FCAV-UNESP, Rod. Prof. Paulo Donato Castellane, s/n, 14884-900 Jaboticabal-SP, <pitelli@fcav.unesp.br> e <plalves@ fcav.unesp.br>; ${ }^{4}$ Aluno de graduação da FCAV-UNESP, Jaboticabal-SP. 


\section{INTRODUÇÃO}

A cultura do milho, tradicionalmente, era conduzida sem muita tecnologia na maior parte do país. Entretanto, nos últimos três anos os indicadores de produtividade apontam para aumento de produtividade e grande avanço na aplicação de tecnologia no campo. Nas últimas três safras, o Brasil obteve produtividade média de 3,2 $\mathrm{t} \mathrm{ha}^{-1}$, o que ainda equivale a um terço da produtividade dos agricultores americanos e à metade da produtividade dos argentinos (Agrianual, 2004). Dentre os fatores que limitam a produtividade do milho, a interferência das plantas daninhas tem grande destaque, não só nas perdas de produção como na composição dos custos. A presença das plantas daninhas em determinadas fases da cultura do milho provoca perdas de produtividade, as quais podem variar de 7 a 100\% (Souza, 1996). A utilização de técnicas culturais adequadas no manejo de plantas daninhas pode constituir importante instrumento para evitar gastos, principalmente nas fases em que a interação entre a cultura e a comunidade infestante ainda não atingiu o período anterior à interferência (PAI).

As plantas de milho apresentam boa capacidade competitiva (Heemst, 1986), estando esta cultura enquadrada no grupo daquelas que mais rapidamente sombreiam o solo (Keeley \& Thullen, 1978). As plantas daninhas podem mobilizar grande quantidade de nutrientes e água do solo e reduzir, portanto, sua disponibilidade às plantas cultivadas, caracterizando a competição pelos recursos do ambiente. Crowder \& Cheda (1992, citado por Sengik et al., 1996) observam que na maior parte dos solos tropicais a disponibilidade de fósforo para as plantas está abaixo do nível crítico, e esse nutriente constitui-se no mais limitante para o estabelecimento de gramíneas. Behrens (1979) observou que populações naturais de Amaranthus retroflexus e de Chenopodium album mobilizaram duas vezes mais nitrogênio e fósforo e três vezes mais potássio do solo que as plantas de milho. Da mesma forma, vários trabalhos evidenciam a elevada capacidade de mobilização de nutrientes pelas plantas daninhas, em detrimento daquela observada para cultura do milho (Rajan \& Sankaran, 1974; Williams \& Laws,
1975; Cicerelli, 1977; Iwata \& Takayanagi, 1980; Marais, 1985).

Dentre as plantas daninhas infestantes da cultura do milho, a tiririca (Cyperus rotundus) destaca-se como uma das mais importantes. Essa espécie tem distribuição generalizada, sendo considerada planta daninha em mais de 90 países (Bendixen \& Nandihalli, 1987). No Brasil, ela é encontrada em todos os tipos de solos, climas e culturas (Lorenzi, 2000). Nemoto et al. (1994, 1995) constataram acentuada resposta da tiririca à adubação fosfatada. Salvador (1986), em estudos conduzidos em vasos com pequeno volume de solo, observou que a fertilização fosfatada pode alterar as relações de interferência entre plantas de milho e tiririca, modificando a dinâmica de crescimento das plantas. O conhecimento dessas influências pode ser útil como subsídio para futuros programas de manejo integrado de plantas daninhas.

Dessa forma, o objetivo deste estudo foi avaliar a influência da adubação fosfatada sobre o crescimento inicial de plantas de milho e de tiririca, cultivadas isoladamente ou em convivência.

\section{MATERIAL E MÉTODOS}

O trabalho foi conduzido em área experimental do Departamento de Biologia Aplicada à Agropecuária da Faculdade de Ciências Agrárias e Veterinárias, UNESP, Jaboticabal-SP. Utilizaram-se vasos de cimento-amianto de $56 \mathrm{~cm}$ de diâmetro e capacidade para $90 \mathrm{~L}$, mantidos a céu aberto, os quais foram preenchidos com a mistura de terra, areia lavada e substrato da marca comercial Plantmax ${ }^{\circledR}(3: 1: 1 \mathrm{v} / \mathrm{v} / \mathrm{v})$. A análise química da mistura apresentou o seguinte resultado: $\mathrm{pH}$ de 5,3; teor de matéria orgânica de $32 \mathrm{~g} \mathrm{dm}^{-3}$; P de 52,0 mg dm ${ }^{-3} ; \mathrm{K}, \mathrm{Ca}, \mathrm{Mg}, \mathrm{H}+\mathrm{Al}$, SB e CTC de 2,2;27,0; 13,0 22,0; 42,2; e $64,2 \mathrm{mmol}_{\mathrm{c}} \mathrm{dm}^{-3}$, respectivamente; e V\% de 66. $\mathrm{Na}$ adubação de semeadura adicionaram-se 250 e 300 ppm de N e K, nas formas de cloreto de potássio e uréia, respectivamente. O preparo e a fertilização do substrato foram efetuados em betoneira, visando obter a uniformidade da mistura. Aos 30 dias após a semeadura, foi realizada uma adubação em cobertura em toda a superfície do vaso, utilizando sulfato de amônio na dose de $60 \mathrm{~kg} \mathrm{ha}^{-1} \mathrm{de} \mathrm{N}$.

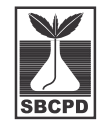


Os vasos foram mantidos espaçados de $1,2 \mathrm{~m}$ entre si. O delineamento experimental adotado foi o inteiramente casualizado, com quatro repetições. Os tratamentos experimentais constaram da combinação de três níveis de adubação fosfatada (0, 100 e 300 ppm) e três densidades de tiririca $(0,25$ e 50 tubérculos por vaso), na presença ou ausência das plantas de milho (Tabela 1). Na adubação fosfatada utilizou-se fosfato monoamônio (MAP) em quantidade suficiente para elevar em 0,100 e 300 ppm os níveis de fósforo da mistura. Na adubação nitrogenada de plantio, as quantidades proporcionais de nitrogênio fornecidas pela adubação com o MAP foram consideradas. Foram semeadas 16 sementes de milho (híbrido Agroceres AG 7575) por vaso, deixando-se no raleamento a densidade constante de oito plantas por vaso. A tiririca foi plantada nas densidades de 25 e 50 tubérculos por vaso. Três dias antes da semeadura do milho e do plantio dos tubérculos de tiririca, estes foram colocados para brotar sobre papelfiltro úmido, transplantando-se, em seguida, somente aqueles que apresentavam início de brotação. Esse procedimento foi realizado para garantir uniformidade na densidade populacional da tiririca nos vasos. O milho foi semeado nos vasos de forma eqüidistante e a tiririca foi plantada de forma aleatória.

Aos 42 dias após a emergência encerrouse o experimento, avaliando-se altura de plantas, área foliar, matéria seca de bainha, colmo e folhas no milho, número e matéria seca de manifestações epígeas e de tubérculos de tiririca. Para avaliação da matéria seca, a parte aérea das plantas foi lavada e colocada em estufa com renovação forçada de ar a $70^{\circ} \mathrm{C}$, até atingir peso constante.

Os dados foram submetidos à análise de variância pelo teste $\mathrm{F}$, sendo as médias comparadas pelo teste de Tukey a $5 \%$ de probabilidade. Para cada espécie, a análise estatística obedeceu a um procedimento distinto: para a tiririca, utilizou-se um esquema fatorial $3 \times 2 \times 2$, em que constituiam variáveis três doses de fósforo, duas condições de colonização do vaso e duas densidades populacionais de tiririca; e, para o milho, os dados foram analisados de acordo com esquema fatorial $3 \times 3$, sendo três condições de colonização do vaso e três doses de fósforo.
Tabela 1 - Concentrações de fósforo visadas na adição do adubo fosfatado, presença do milho e densidades de tiririca, que constituíram os tratamentos experimentais

\begin{tabular}{|c|c|c|c|}
\hline Tratamento & $\begin{array}{c}\text { Teor de fósforo } \\
\text { (ppm) }\end{array}$ & $\begin{array}{c}\text { Plantas de } \\
\text { milho por vaso }\end{array}$ & $\begin{array}{c}\text { Tubérculos de } \\
\text { tiririca por } \\
\text { vaso }\end{array}$ \\
\hline 1 & 0 & 8 & 0 \\
\hline 2 & 100 & 8 & 0 \\
\hline 3 & 300 & 8 & 0 \\
\hline 4 & 0 & 8 & 25 \\
\hline 5 & 100 & 8 & 25 \\
\hline 6 & 300 & 8 & 25 \\
\hline 7 & 0 & 8 & 50 \\
\hline 8 & 100 & 8 & 50 \\
\hline 9 & 300 & 8 & 50 \\
\hline 10 & 0 & 0 & 25 \\
\hline 11 & 100 & 0 & 0 \\
\hline 12 & 300 & 0 & 25 \\
\hline 13 & 0 & 0 & 50 \\
\hline 14 & 100 & 0 & 50 \\
\hline 15 & 300 & 0 & 50 \\
\hline
\end{tabular}

\section{RESULTADOS E DISCUSSÃO}

Para os dados de matéria seca de colmos, bainha e limbo foliar, bem como para a área foliar, os efeitos ocorreram em função das densidades de tiririca ou da adubação fosfatada, sem se observar interação entre esses fatores. Portanto, a produção de matéria seca do milho em resposta à adição de $\mathrm{P}$ foi similar para as três condições de colonização dos vasos e vice-versa (Tabela 2 ).

Com o aumento das doses de $\mathrm{P}$, houve aumento significativo na matéria seca de colmos e folhas e, também, na área foliar; contudo, apenas na maior dose de P (300 ppm) verificou-se incremento significativo na matéria seca de bainhas, em comparação às demais doses de P (Tabela 2). Dentre essas características, a matéria seca dos colmos foi a que apresentou maior resposta (acúmulo de 355\%) quando a dose de $\mathrm{P}$ foi aplicada. Provavelmente isso ocorreu em função do aumento do diâmetro dos colmos, uma vez que o aumento na altura foi pouco expressivo (22\%).

A resposta da cultura do milho à adubação fosfatada, também observada em outros estudos (Engelbrecht, 1980; Salvador, 1986), provavelmente ocorreu em virtude da elevada 
demanda por P para o seu crescimento inicial, além da escassez deste elemento em solos tropicais (Malavolta, 1980). Essa elevada demanda inicial de nutrientes pelas plantas de milho é uma das causas da preocupação com o controle das plantas daninhas no início do ciclo da cultura.

Reduções médias significativas na produção de matéria seca dos colmos e folhas e na área foliar foram observadas devido à interferência da tiririca, independentemente da densidade dessa planta daninha; todavia, não se verificou efeito significativo da densidade de tiririca sobre a matéria seca da bainha (Tabela 2).

Para altura das plantas de milho houve interação significativa entre doses de $\mathrm{P}$ e densidade de tiririca (Tabela 2). Logo, o desdobramento dessa interação reveste-se de grande importância, uma vez que, dada a distância entre os vasos e o porte da tiririca, não ocorreu estiolamento. O efeito da interferência da tiririca sobre a altura das plantas de milho ocorreu nas doses de 0 e $100 \mathrm{ppm}$ de $\mathrm{P}$ (Tabela 3). A adubação com 300 ppm de P praticamente anulou os efeitos de interferência da tiririca na altura das plantas de milho. Esse resultado sugere que parte da interferência da tiririca sobre a cultura pode ter ocorrido pela competição por P. Comparando-se os efeitos da adubação dentro de cada densidade da planta daninha, não houve efeitos da adição de 100 ppm de P na altura das plantas de milho sob infestação de 25 e 50 tubérculos de tiririca por vaso; contudo, esse efeito foi significativo na maior dose de P. Esse resultado traduz-se em outra evidência: de que a competição por $\mathrm{P}$ possa ter constituído um fator de interferência.

Os efeitos negativos da interferência da tiririca no crescimento inicial de plantas de milho já foram destacados em trabalhos anteriores por inúmeros autores, como Engelbrecht (1980, 2004) Salvador (1986) e Carvalho (1992).

É importante ressaltar que não houve diferenças entre as densidades de tiririca de 25 e 50 tubérculos por vaso para todas as características avaliadas (Tabela 2). Esse fato pode estar relacionado a alguns comportamentos dessa planta daninha: ela pode apresentar a compensação populacional pela maior produção de biomassa por unidade reprodutiva quando plantada em menores densidades, pois na menor densidade houve a produção de

Tabela 2 - Resultados da análise de variância e valores médios das variáveis matéria seca de colmos, bainhas e limbo foliar, área foliar e altura de plantas de milho, em função das doses de $\mathrm{P}$ e densidades de tiririca

\begin{tabular}{|c|c|c|c|c|c|}
\hline \multicolumn{6}{|c|}{ Variável } \\
\hline \multirow{2}{*}{ Fator } & \multicolumn{3}{|c|}{ Matéria seca $(\mathrm{g})$} & \multirow{2}{*}{ Área foliar $\left(\mathrm{cm}^{2}\right)$} & \multirow{2}{*}{ Altura $(\mathrm{cm})$} \\
\hline & Colmos & Bainhas & Folhas & & \\
\hline \multicolumn{6}{|c|}{ Densidade (D) } \\
\hline 0 & $14,50 \mathrm{a}$ & $32,62 a$ & $72,35 \mathrm{a}$ & $11.850,99 \mathrm{a}$ & $27,43 a$ \\
\hline 25 & $9,19 b$ & $23,63 a$ & $53,15 b$ & $9.055,18 \mathrm{~b}$ & $25,37 \mathrm{~b}$ \\
\hline 50 & $8,57 \mathrm{~b}$ & $24,85 \mathrm{a}$ & $48,30 \mathrm{~b}$ & $8.948,73 \mathrm{~b}$ & $25,18 \mathrm{~b}$ \\
\hline $\mathrm{F}$ & $10,14 * *$ & $2,61 \mathrm{~ns}$ & $24,28 * *$ & $13,65 * *$ & $11,81 * *$ \\
\hline DMS 5\% & 3,58 & 10,57 & 9,05 & 1562,49 & 1,23 \\
\hline \multicolumn{6}{|c|}{ Dose de $\mathrm{P}(\mathrm{P})$} \\
\hline 0 & $4,10 \mathrm{c}$ & $16,70 \mathrm{~b}$ & $43,20 \mathrm{c}$ & $7.633,56 \mathrm{c}$ & $23,30 \mathrm{c}$ \\
\hline 100 & $9,50 \mathrm{~b}$ & $25,30 \mathrm{~b}$ & $58,35 \mathrm{~b}$ & $9.961,15 b$ & $26,19 \mathrm{~b}$ \\
\hline 300 & $18,65 \mathrm{a}$ & $39,10 \mathrm{a}$ & $72,25 \mathrm{a}$ & $12.260,19 \mathrm{a}$ & $28,49 \mathrm{a}$ \\
\hline $\mathrm{F}$ & $51,79 * *$ & $14,03 * *$ & $31,72 * *$ & $26,97 * *$ & $51,48^{* *}$ \\
\hline DMS 5\% & 3,58 & 10,57 & 9,05 & $1.562,49$ & 1,23 \\
\hline $\mathrm{F}(\mathrm{DxP})$ & $1,34 \mathrm{~ns}$ & $1,05 \mathrm{~ns}$ & $0,087 \mathrm{~ns}$ & $0,18 \mathrm{~ns}$ & $5,02 * *$ \\
\hline $\mathrm{CV}(\%)$ & 32,9 & 38,6 & 15,4 & 15,5 & 6,8 \\
\hline
\end{tabular}

ns - não-significativo pelo teste $\mathrm{F}$ a $5 \%$ de probabilidade; ** - significativo pelo teste $\mathrm{F}$ a $1 \%$ de probabilidade. Para cada fator, médias seguidas da mesma letra na coluna não diferem entre si. 
2,38 g de matéria seca por tubérculo, enquanto na maior densidade a produção foi de $1,59 \mathrm{~g}$ (Tabela 4); a interferência indireta, afetando a disponibilidade de certos elementos no substrato, como é o caso do nitrogênio perdido por atividade de flora denitrificante incentivada por exsudatos radiculares da tiririca; e a atividade alelopática exercida pela tiririca sobre as plantas de milho. Acredita-se que estas últimas formas de interferência não sejam densodependentes; ao contrário, quanto menos colonizado o meio, maior será o esforço de interferência por parte da planta daninha para que possa completar sua colonização. De qualquer maneira, os valores tenderam a ser menores nas maiores densidades, e, numa comparação entre as parcelas sem tiririca e aquelas com densidade inicial de 50 tubérculos por vaso, o colmo experimentou a maior redução de matéria seca acumulada (40,9\%). As reduções na matéria seca de folhas e na área foliar foram de 33,2 e 24,5\%, respectivamente.

Analisando os dados referentes às plantas de tiririca, na Tabela 4 podem ser observadas

Tabela 3 - Desdobramento da interação entre densidade de tubérculos de tiririca e doses de fósforo para a altura de plantas de milho, aos 42 dias após a semeadura

\begin{tabular}{|c|c|c|c|c|}
\hline \multirow{2}{*}{ Densidade } & \multicolumn{3}{|c|}{ Dose de P (ppm) } & \multirow{2}{*}{$\mathrm{F}$} \\
\cline { 2 - 5 } & 0 & 100 & 300 & \\
\hline 0 & $26,06 \mathrm{Ba}$ & $27,52 \mathrm{ABa}$ & $28,71 \mathrm{Aa}$ & $4,4607 *$ \\
\hline 25 & $22,97 \mathrm{Bb}$ & $24,88 \mathrm{Bb}$ & $28,25 \mathrm{Aa}$ & $18,0552^{* *}$ \\
\hline 50 & $20,86 \mathrm{Cb}$ & $26,17 \mathrm{Bab}$ & $28,52 \mathrm{Aa}$ & $39,0132^{* *}$ \\
\hline $\mathrm{F}$ & $17,3149 * *$ & $4,4037 *$ & $0,1370 \mathrm{~ns}$ & \\
\hline
\end{tabular}

ns - não-significativo pelo teste $\mathrm{F}$ a $5 \%$ de probabilidade; * significativo pelo teste $\mathrm{F}$ a $5 \%$ de probabilidade; $* *$ - significativo pelo teste $\mathrm{F}$ a $1 \%$ de probabilidade. Médias seguidas de mesma letra, maiúscula na linha e minúscula na coluna, não diferem significativamente entre si a $5 \%$ de probabilidade pelo teste de Tukey.

Tabela 4 - Análise de variância e valores médios de número e matéria seca de tubérculos e manifestações epígeas de plantas de tiririca em função das doses de $\mathrm{P}$ e densidades de tiririca

\begin{tabular}{|c|c|c|c|c|}
\hline \multirow{2}{*}{ Fator } & \multicolumn{2}{|c|}{ Número por vaso } & \multicolumn{2}{|c|}{ Matéria seca por vaso } \\
\hline & Tubérculos & Manifestações epígeas & Tubérculos & Manifestações epígeas \\
\hline \multicolumn{5}{|c|}{ Condição de colonização (A) } \\
\hline Com milho & $196,79 b$ & $127,08 \mathrm{~b}$ & $26,59 \mathrm{~b}$ & $25,17 \mathrm{~b}$ \\
\hline Sem milho & $308,79 a$ & $206,08 \mathrm{a}$ & $40,52 \mathrm{a}$ & $46,54 \mathrm{a}$ \\
\hline $\mathrm{F}$ & $19,12^{* *}$ & $34,68 * *$ & $6,16^{*}$ & $22,27 * *$ \\
\hline DMS 5\% & 51,97 & 27,22 & 11,38 & 9,18 \\
\hline \multicolumn{5}{|c|}{ Densidade de tiririca (B) } \\
\hline 25 & $204,25 b$ & $138,37 \mathrm{~b}$ & $27,85 b$ & $31,61 \mathrm{a}$ \\
\hline 50 & $301,33 \mathrm{a}$ & $194,79 \mathrm{a}$ & $39,26 \mathrm{a}$ & $40,10 \mathrm{a}$ \\
\hline $\mathrm{F}$ & $14,36^{* *}$ & $17,69 * *$ & $4,14 *$ & $3,51 \mathrm{~ns}$ \\
\hline DMS 5\% & 51,97 & 27,22 & 11,38 & 9,18 \\
\hline \multicolumn{5}{|c|}{ Doses de fósforo (C) } \\
\hline 0 & $220,18 \mathrm{a}$ & $147,62 b$ & $28,16 \mathrm{a}$ & $23,66 \mathrm{~b}$ \\
\hline 100 & $258,93 \mathrm{a}$ & $166,68 \mathrm{a}$ & $32,54 \mathrm{a}$ & $34,72 \mathrm{~b}$ \\
\hline 300 & $279,25 \mathrm{a}$ & $185,43 \mathrm{a}$ & $39,96 a$ & $49,20^{\mathrm{a}}$ \\
\hline $\mathrm{F}$ & $1,83 \mathrm{NS}$ & $2,64 \mathrm{~ns}$ & $1,51 \mathrm{~ns}$ & $10,67 * *$ \\
\hline DMS 5\% & 76,67 & 40,15 & 16,78 & 13,55 \\
\hline $\mathrm{F}(\mathrm{A} \times \mathrm{B})$ & $2,35 \mathrm{~ns}$ & $4,54 *$ & $0,68 \mathrm{~ns}$ & $2,74 \mathrm{~ns}$ \\
\hline$F(A \times C)$ & $5,85 * *$ & $2,4230 \mathrm{~ns}$ & $1,84 \mathrm{~ns}$ & $6,25 * *$ \\
\hline $\mathrm{F}(\mathrm{B} \times \mathrm{C})$ & $0,12 \mathrm{~ns}$ & $0,0463 \mathrm{~ns}$ & $0,35 \mathrm{~ns}$ & $0,07 \mathrm{~ns}$ \\
\hline $\mathrm{F}(\mathrm{AxBxC})$ & $0,42 \mathrm{~ns}$ & 0,4240ns & $0,27 \mathrm{~ns}$ & $0,48 \mathrm{~ns}$ \\
\hline $\mathrm{CV}$ & 35,09 & 27,89 & 57,89 & 43,72 \\
\hline
\end{tabular}

ns - não-significativo pelo teste $\mathrm{F}$ a $5 \%$ de probabilidade. ** - significativo pelo teste $\mathrm{F}$ a $1 \%$ de probabilidade. Para cada fator, médias seguidas da mesma letra na coluna não diferem entre si. 
reduções significativas nos números e nas matérias secas de tubérculos e manifestações epígeas em decorrência da interferência do milho. Esses efeitos já haviam sido observados por vários autores (Engelbrecht, 1980; Salvador, 1986, 2004; Carvalho, 1992). A tiririca é uma planta com metabolismo fotossintético $\mathrm{C}_{4}$, sendo, portanto, altamente suscetível ao sombreamento, sofrendo forte redução de crescimento com a limitação da radiação solar, como aquele causado pelas plantas de milho (Nemoto et al., 1994, 1995). Das características estudadas nas plantas de tiririca, o número e a matéria seca da parte aérea mostraram maiores reduções quando comparados com os dados de tubérculos; além disso, a relação entre a matéria seca da parte aérea e a dos tubérculos foi de 0,95 nos tratamentos com tiririca crescendo isolada e de 1,15 na presença do milho. Esse tipo de comportamento corrobora observações efetuadas por Engelbrecht (1980) e Salvador (1986, 2004), de que, sob interferência do milho, a tiririca mobiliza maior quantidade de recursos para as estruturas reprodutivas, provavelmente como forma de garantir a sobrevivência da população.

Independentemente da densidade inicial, houve similaridade estatística na matéria seca de manifestações epígeas produzidas no período experimental. O número de tubérculos foi significativamente maior nos tratamentos com a densidade inicial de 50 tubérculos por vaso, sugerindo menor tamanho médio dessas estruturas vegetativas. O número e a matéria seca de tubérculos foram maiores nos vasos em que foi realizado o plantio de 50 tubérculos; provavelmente, isso ocorreu em função do aumento do número de unidades, pois a matéria seca média de tubérculo foi de 136 e $130 \mathrm{mg}$ para os vasos com densidades iniciais de 25 e 50 tubérculos, respectivamente. Os números de tubérculos produzidos por unidade plantada foram de 8,17 e 6,03 para as densidades iniciais de 25 e 50 tubérculos por vaso, respectivamente. Esse comportamento sugere um certo grau de competição intraespecífica na população da tiririca.

As respostas da tiririca à fertilização fosfatada foram pequenas, uma vez que não houve efeito significativo sobre o milho e a matéria seca de tubérculos, apesar de incrementos de
26,8 e $41,9 \%$ no número e na matéria seca de tubérculos terem sido observados entre as doses de 0 e $300 \mathrm{ppm}$ de $\mathrm{P}$, respectivamente.

Os incrementos observados no número e na matéria seca de manifestações epígeas da tiririca, comparando-se adubações com 0 e $300 \mathrm{ppm}$ de $\mathrm{P}$, foram de 25,6 e 107,9\%, respectivamente. Houve significância estatística para os dados de matéria seca e número de manifestações epígeas. Quando encontra condições ótimas para seu crescimento e desenvolvimento, como, por exemplo, sob elevada disponibilidade de $\mathrm{P}$, a tiririca mobiliza mais recursos para o crescimento vegetativo, provavelmente para aproveitar as boas condições para produção de fotoassimilados e, conseqüentemente, seu transporte às estruturas reprodutivas (Salvador, 1986; Nemoto et al., 1994, 1995).

O desdobramento dos graus de liberdade da interação entre condição de colonização dos vasos e fertilização fosfatada evidenciou que os efeitos da interferência do milho sobre o número e a matéria seca de manifestações epígeas foram significativos nos tratamentos com fertilização fosfatada (Tabela 5). Nos grupos de parcelas que receberam $0,100 \mathrm{e}$ $300 \mathrm{ppm}$ de $\mathrm{P}$, as reduções nos números de manifestações epígeas em decorrência da interferência do milho foram de 2,1, 35,6 e 56,4\%, respectivamente, enquanto na matéria seca da parte aérea elas foram de $14,1,41,4$ e 60,2\%, respectivamente. Esses resultados sugerem que, nas parcelas sem adubação, o fósforo foi um fator importante e limitante ao crescimento da tiririca; quando seus níveis foram elevados, a interferência do milho passou a assumir maior importância na limitação do crescimento populacional da planta daninha. É interessante destacar que as respostas do milho à adubação fosfatada foram mais intensas que as da tiririca. Ademais, comparando os efeitos das doses do P nos grupos de parcelas em que a tiririca cresceu isolada ou sob interferência do milho (Tabela 5), verificou-se que na presença do milho não houve resposta da tiririca à adubação com $\mathrm{P}$, mas na ausência da cultura ela foi bastante intensa. Essas respostas foram similares às obtidas por Engelbrecht (1980) e Salvador (1986) em vasos com capacidade para $1,0 \mathrm{~L}$ de solo. 
Tabela 5 - Desdobramento da interação entre condição de colonização e doses de P sobre número de tubérculos e matéria seca de manifestações epígeas de tiririca, aos 42 dias após o plantio

\begin{tabular}{|c|c|c|c|c|c|}
\hline \multirow{2}{*}{\multicolumn{2}{|c|}{ Condição de Colonização }} & \multicolumn{3}{|c|}{ Doses de P (ppm) } & \multirow{2}{*}{$\mathrm{F}$} \\
\hline & & 0 & 100 & 300 & \\
\hline \multicolumn{6}{|c|}{ Numero de manifestações epígeas } \\
\hline \multirow{3}{*}{ Milho } & Presente & $217,87 \mathrm{Aa}$ & $202,87 \mathrm{Ab}$ & $169,62 \mathrm{Ab}$ & $0,6197 \mathrm{~ns}$ \\
\hline & Ausente & $222,50 \mathrm{Ba}$ & $315,00 \mathrm{ABa}$ & $388,87 \mathrm{Aa}$ & $7,0623 * *$ \\
\hline & $\mathrm{F}$ & $0,0109 \mathrm{~ns}$ & $6,3880^{*}$ & $24,4269 * *$ & \\
\hline \multicolumn{6}{|c|}{ Matéria seca de manifestações epígeas } \\
\hline \multirow{3}{*}{ Milho } & Presente & $21,87 \mathrm{Aa}$ & $25,66 \mathrm{Ab}$ & $28,00 \mathrm{Ab}$ & $0,3108 \mathrm{~ns}$ \\
\hline & Ausente & $25,45 \mathrm{Ba}$ & $43,78 \mathrm{Ba}$ & $70,40 \mathrm{Aa}$ & $16,6196 * *$ \\
\hline & $\mathrm{F}$ & $0,2079 \mathrm{~ns}$ & $5,3439 *$ & $29,2439 * *$ & \\
\hline
\end{tabular}

ns - não-significativo pelo teste $\mathrm{F}$ a $5 \%$ de probabilidade; * - significativo pelo teste $\mathrm{F}$ a $5 \%$ de probabilidade; $* *$ - significativo pelo teste $\mathrm{F}$ a $1 \%$ de probabilidade. Médias seguidas de mesma letra, maiúscula na linha e minúscula na coluna, não diferem significativamente entre si a 5\% de probabilidade pelo teste de Tukey.

Quanto ao desdobramento dos graus de liberdade da interação entre condições de colonização (presença ou não do milho) e densidade de tiririca no número de manifestações epígeas desta, constatou-se que, independentemente do número de tubérculos, a presença das plantas de milho causou redução significativa no número de manifestações epígeas (Tabela 6), enquanto na ausência destas plantas houve incremento significativo dessa variável.

Tabela 6 - Desdobramento da interação entre condições de colonização e densidade de tiririca no número de manifestações epígeas de tiririca, aos 42 dias após o plantio

\begin{tabular}{|c|c|c|c|l|}
\hline \multicolumn{2}{|c|}{$\begin{array}{c}\text { Condição de } \\
\text { Colonização }\end{array}$} & \multicolumn{2}{|c|}{$\begin{array}{c}\text { Densidade de tiririca } \\
\text { (planta por vaso) }\end{array}$} & \multirow{2}{*}{ F } \\
\cline { 3 - 4 } & & 25 & 50 & \\
\hline \multirow{2}{*}{ Milho } & Presente & $113,16 \mathrm{Ab}$ & $141,00 \mathrm{Ab}$ & $2,1529 \mathrm{NS}$ \\
& Ausente & $163,58 \mathrm{Ba}$ & $248,58 \mathrm{Aa}$ & $20,0789 * *$ \\
\hline & $\mathrm{F}$ & $7,0640 *$ & $32,1656 * *$ & \\
\hline
\end{tabular}

ns - não-significativo pelo teste $\mathrm{F}$ a $5 \%$ de probabilidade; * significativo pelo teste $\mathrm{F}$ a $5 \%$ de probabilidade; ** - significativo pelo teste $\mathrm{F}$ a $1 \%$ de probabilidade. Médias seguidas de mesma letra, maiúscula na linha e minúscula na coluna, não diferem significativamente entre si a $5 \%$ de probabilidade pelo teste de Tukey.

As relações de interferência entre plantas de milho e de tiririca podem, portanto, ser alteradas pela fertilização fosfatada do solo. $\mathrm{O}$ milho interfere mais decisivamente sobre a tiririca em solos bem fertilizados com P.

\section{LITERATURA CITADA}

AGRIANUAL: Anuário da Agricultura Brasileira. São Paulo: FNP Consultoria e Comércio, 2004. p. 373-395.

BEHRENS, R. Weed control in U. S. maize. In: CIBA. Maize, 1979. p. 38-45.

BENDIXEN, L. E.; NANDIHALLI, U. B. Worldwide distribution of purple and yellow nutsedge (Cyperus rotundus and Cyperus esculentus). Weed Techn., v. 1, p. 61-65, 1987.

CARVALHO, P. F. O. Efeitos da interferência entre Cyperus rotundus L. e Zea mays L. sobre os componentes fenológicos das plantas. 1992. $37 \mathrm{f}$. (Trabalho de Graduação) Universidade Estadual Paulista, Jaboticabal, 1992.

\section{CICERELLI, L. G. Composição química de alguns} infestantes da cultura do milho. 1977. 32 f. Monografia (Trabalho de Graduação em Agronomia) - Universidade Estadual Paulista, Jaboticabal, 1977.

ENGELBRECHT, F. Efeitos da fertilização do solo sobre as relações competitivas iniciais entre Cyperus rotundus L. e Zea mays L., 1980, 54 f. Trabalho de Graduação Universidade Estadual Paulista, Jaboticabal, 1980.

HEEMST, H. D. G. The influence of weed competition on crop yield. Agric. System, v. 18, n. 2, p. 81-89, 1986.

IWATA, L.; TAKAYANAGI, S. Studies on the damage to upland crops by weeds: the effects of weed competition on the growth and yield of crops. Weed Res., v. 25, n. 3 , p. 200-206, Weed Abst., v. 30, n. 11, p. 449, 1980.

KEELEY, P. E.; THULLEN, R. J. Light requirements of yellow nutsedge and light interception by crops. Weed Sci., v. 26, n. 1, p. 10-16, 1978.

Planta Daninha, Viçosa-MG, v. 24, n. 1, p. 37-44, 2006 
LORENZI, H. Plantas daninhas do Brasil: terrestres, aquáticas, parasitas e tóxicas. 3.ed. Nova Odessa:

Plantarum, 2000. 349 p.

MALAVOLTA, E. Elementos de nutrição mineral de plantas. São Paulo: Agronômica Ceres, 1980. 251 p.

MARAIS, J. N. Weed competition in maize with reference to peasent farming. Fort Hare Papers, v. 8, n. 1, p. 63-82, 1985 .

NEMOTO, M. C. M. et al. Comportamento da tiririca (Cyperus rotundus L.) sob diferentes níveis de adubação fosfatada e sombreamento. Planta Daninha, v. 13, n. 1, p. 50-55, 1995.

NEMOTO, M. C. M. et al. Efeitos do sombreamento e da adubação fosfatada sobre aspectos biológicos da tiririca (Cyperus rotundus L.). Cult. Agron., v. 3, n. 1, p. 129-142, 1994.

RAJAN, A. V.; SANKARAN, S. Studies on crop weed competition for nutrient and its effect on grain yield of maize. Madras Agric. J., v. 61, n. 8, p. 413-416, 1974.
SALVADOR, F. C. Estudo de competição inter e intraespecífica envolvendo plantas de Cyperus rotundus e de milho doce. 2004. 58 f. (Trabalho de Graduação) Universidade Estadual Paulista, Jaboticabal, 2004.

SALVADOR, P. C. Estudo da interferência entre tiririca (Cyperus rotundus L.) e a cultura do milho (Zea mays L.), em condições de casa-de-vegetação. 1986. 42 f.

(Trabalho de Graduação) - Universidade Estadual Paulista, Jaboticabal, 1986.

SENGIK, E. et al. Efeito da adubação por subtração de nutrientes na produção de massa seca do milho (Zea mays L.) e do capim-tanzânia (Panicum maximun Jacp. Cv. Tanzânia) em terra ácida. R. Unimar, v. 18, n. 3, p. 521-523, 1996.

SOUZA, J. R. P. Efeitos de períodos de controle de plantas daninhas sobre o crescimento e produtividade de quatro híbridos de milho (Zea mays L.). 1996. 89 f. Tese (Doutorado em Agronomia) - Universidade Estadual Paulista, Botucatu, 1996.

WILLIAMS, C. F.; LAWS, W. D. Effects of weed competition on the growth of sweet corn. Hortscience, v. 10, n. 3 , p. $311,1975$. 